\title{
Potential contribution of beneficial microbes to face the COVID-19 pandemic
}

\author{
Adriane E.C. Antunes ${ }^{\mathrm{a}}$, Gabriel Vinderola ${ }^{\mathrm{b}}$, Douglas Xavier-Santos ${ }^{\mathrm{a}}$, Katia Sivieri ${ }^{\mathrm{c}, *}$ \\ ${ }^{a}$ School of Applied Sciences (FCA), State University of Campinas, 1300 Pedro Zaccaria St, Zip Code 13484-350 Limeira, SP, Brazil \\ ${ }^{\mathrm{b}}$ Instituto de Lactología Industrial (INLAIN, UNL-CONICET), Facultad de Ingeniería Química, Universidad Nacional del Litoral, Santiago del Estero 2829, Santa Fe 3000, \\ Argentina \\ ${ }^{\mathrm{c}}$ Department of Food and Nutrition, School of Pharmaceutical Sciences, São Paulo State University (UNESP), Rodovia Araraquara Jaú km 1, Zip Code 14800-903 \\ Araraquara, SP, Brazil
}

\section{A R T I C L E I N F O}

\section{Keywords:}

SARS-CoV-2

Coronavirus disease

Microbiota

Fermented foods

Probiotics

Prebiotics

\begin{abstract}
A B S T R A C T
The year 2020 will be remembered by a never before seen, at least by our generation, global pandemic of COVID19. While a desperate search for effective vaccines or drug therapies is on the run, nutritional strategies to promote immunity against SARS-CoV-2, are being discussed. Certain fermented foods and probiotics may deliver viable microbes with the potential to promote gut immunity. Prebiotics, on their side, may enhance gut immunity by selectively stimulating certain resident microbes in the gut. Different levels of evidence support the use of fermented foods, probiotics and prebiotics to promote gut and lungs immunity. Without being a promise of efficacy against COVID-19, incorporating them into the diet may help to low down gut inflammation and to enhance mucosal immunity, to possibly better face the infection by contributing to diminishing the severity or the duration of infection episodes.
\end{abstract}

\section{Introduction}

An outbreak of coronavirus disease (COVID-19), caused by severe acute respiratory syndrome (SARS-CoV-2), has rapidly spread from China to almost all over the world affecting over 13,200,000 people across 199 countries by early July 2020. By that time, more than 577,000 people were lost to the virus (John Hopkins University, 2020).

The SARS-CoV-2 coronavirus is part of a family of viruses, known as coronaviruses, common in nature, with many potential natural primary, intermediate, and final hosts (Wang et al., 2020). These viruses cause respiratory infections, such as the severe acute respiratory syndrome SARS (whose agent is SARS-CoV) and the Middle East respiratory syndrome - MERS (whose agent is MERS-CoV). In the past, human coronaviruses (HCoVs) have been considered to be relatively harmless respiratory pathogens till the outbreaks SARS and MERS (Yin \& Wunderink, 2018). Due to the fact that SARS-CoV-2 is $96 \%$ identical at the whole-genome level to a bat coronavirus, the domestication and/or consumption of wildlife animal was pointed as the possible origin for the disease (Wu et al., 2020).

COVID-19 has emerged as a multifaceted, multi-system and multiorgan disorder ranging from non-specific flulike symptoms, to pneumonia, acute respiratory distress syndrome (ARDS), multiple organ failure and death (Baud et al., 2020; Chen et al., 2020; Infusino et al., 2020). Other described clinical findings are: septic shock, metabolic acidosis and coagulation dysfunction (Infusino et al., 2020). Fortunately, most patients have mild symptoms and present good prognosis (Chen et al., 2020).

Coronavirus entry is mediated by the viral spike (S) glycoprotein. Then, SARS-CoV-2 binds to the angiotensin-converting enzyme 2 (ACE2) (Bosch et al., 2003). Binding to ACE2 allows the virus to invade cells in the oropharyngeal epithelia and the development of lung injury and hyperinflammation (Rivellese \& Prediletto, 2020; Xu, Zhong, et al., 2020). At the pulmonary level ACE2 is expressed on the epithelial cells of alveoli, trachea, bronchi, bronchial serous glands, alveolar monocytes and macrophages (Yin \& Wunderink, 2018). It has been postulated that different concentrations and/or activation of ACE2 at the pulmonary level can be a reason for higher incidence of COVID-19 in adults, compared to children (Fanos et al., 2020).

Interestingly, Zhang et al. (2020) showed that ACE2 is not only highly expressed in the lung AT2 cells, esophagus upper and stratified epithelial cells but also in absorptive enterocytes from ileum and colon. These results indicated along with respiratory systems, that the digestive system is a potential route for 2019-nCov infection.

In this way, the ACE2 has a specific function in intestinal tract,

\footnotetext{
* Corresponding author.

E-mail address: katia.sivieri@unesp.br (K. Sivieri).
} 
regulating intestinal amino acid homeostasis, expression of antimicrobial peptides, and the ecology of the gut microbiome. In additional, ACE2-dependent changes in epithelial immunity and the gut microbiota can be directly regulated by the dietary amino acid tryptophan. Then, ACE2 is key regulator of dietary amino acid homeostasis, innate immunity, gut microbial ecology, and transmissible susceptibility to colitis (Hashimoto et al., 2012).

The role of non-pharmacological substances such as probiotics and nutraceuticals can be an interesting option considering the long time necessary to find, evaluate and produce drugs that are able to interfere with SARS-CoV-2 pathway (Infusino et al., 2020). This review aims to discuss the possible correlation between COVID-19 infection and microbiota. In addition, we show scientific evidence on the possible role of consumption of fermented foods, as well as probiotics and prebiotics in promoting mucosal immunity to better face a possible infection.

\section{COVID-19 affecting intestinal tract}

The most common symptoms of COVID-19 at the onset of illness are fever, cough, fatigue, myalgia, dyspnea, headache, stomachache, pains in the rib cage, loss of taste and smell, skin problems like hives or chills on the toes, neurological problems and gastrointestinal (GI) symptoms, such as diarrhea and nausea (Huang et al., 2020).

Tissue tropism of coronavirus in the intestinal tract was first described by Leung et al. (2003) for the SARS-CoV responsible for the SARS outbreak in Hong Kong in March 2003. It was reported the presence of active viral replication in the small and large intestine of the patients, and also evidence of virus accumulation inside endoplasmic reticulum of enterocytes (Leung et al., 2003).

A lot of evidence shows that human-to-human transmission occurs in close contact, mainly transmitted through respiratory droplets, aerosols and direct contact. Many findings suggest that the intestine could also have a relevant role both in the COVID-19 evolution and as a possible route of infection, so an oral fecal route has also been evaluated (Infusino et al., 2020; Li et al., 2020). Viral RNA from SARS-CoV2 can be found in stools of previously infected patient, even after negativization in the exam from the respiratory tract (Infusino et al., 2020). According to Zhang et al. (2020) enteric symptom of diarrhea would be associated with the invaded ACE2-expressing enterocytes. Even so more studies are needed to confirm this hypothesis.

Jin et al. (2020) evaluated patients with COVID-19 in the Zhejiang province. $11.4 \%$ of these patients (average age of 46.14 years) presented with at least one GI symptom (nausea, vomiting or diarrhea), and GI symptoms were recorded on admission, precluding the influence of other medical therapy and external factors. Li et al. (2020) evaluated 95 cases with SARS-CoV-2 caused coronavirus disease 2019. Among them, 58 cases exhibited GI symptoms (diarrhea, anorexia, and nausea) of which $11.6 \%$ occurred on admission and $49.5 \%$ developed during hospitalization. However, the authors did not correlated the drug administration and GI symptoms. They found presence of SARS-CoV-2 in faecal samples in $52.4 \%$ of patients and SARS-CoV-2 RNA was detected in oesophagus, stomach, duodenum, and rectum specimens for both two severe patients. In addition, patients with GI symptoms revealing oesophagus bleeding with erosions and ulcers.

The more detailed information on the characteristics of COVID-19 is found for adult and elder people, but for children is still scarce. A recent publication showed five children with non-respiratory symptoms as the first manifestation were hospitalized from the emergency department at the Wuhan Children's Hospital and were later confirmed to have COVID-19. Interestingly, that two of these patients had acute gastroenteritis symptoms (Cai et al., 2020).

Viral replication in the intestine determines an exponential increase in the viral load in the digestive mucosa, leading to a loss of barrier integrity and a strong production of cytokines (Infusino et al., 2020).

\section{A shrinking microbiota: An immunocompromised individual}

The term human microbiota refers to the set of microorganisms that we host as human beings. We are colonized on the outside (skin, eyes) and inside (vagina, oral, respiratory, and intestinal tract mucosa) by a large number of bacteria (Bacteroides, Clostridium, Faecalibacterium, Eubacterium, Ruminococcus, Peptococcus, Peptostreptococcus, and Bifidobacterium), fungi (Aspergillus, Candida, Debaryomyces, Malassezia, Penicillium, Pichia, and Saccharomyces), protozoa (Cryptosporidium spp., Giardia intestinalis, Entamoeba histolytica), archaea (Methanobacterium and Woesearchaeota), and even viruses (Enterovirus, Rotavirus, Norovirus), which are essential for life (Thursby \& Juge, 2017). In particular, the intestinal microbiota, formerly known as "intestinal flora", is the set of microbes, mainly bacteria, that colonize the small and large intestine, being the colon the portion of the intestine that hosts the greatest amount and diversity of bacteria. These intestinal bacteria remain active and functional by being feed an essential, but often disregarded, part of the food: fibers. Through the intestinal fermentation of the food fiber, gut microbes manage to reproduce, to cover our intestine mucosa and to exert numerous functions. Some of these are the complementary digestion of the food, the synthesis of anti-inflammatory substances such as butyric acid, the reinforcement of the intestinal epithelial barrier, the prevention of infections and, perhaps their most important function, the modulation of the gut associated lymphoid tissue to promote and modulate gut and systemic immunity. Most of the immune cells, the army that keep alert to possible infections from undesirable bacteria and viruses, are housed in the intestine. The interaction of the microbiota with the immune cells train naïve cells, so that they can fulfil their role of defense against external challenges (Rooks \& Garrett, 2016). Additionally, the gut is related to the brain through a two-way communication route, mediated by intestinal neurons that reach the brain and numerous effector molecules (neurotransmitters, cytokines) that travel in both directions through what is called the gut-brain axis. It is curious, but over $90 \%$ of serotonin, one of the neurotransmitters responsible for regulating mood, social behavior, appetite, digestion or sleep, is produced in the gut (Cryan et al., 2019).

The acquisition of microbiota is a dynamic process that begins at birth and reaches maturity in the first 2-3years of life. This is a period where a window of opportunities is deployed for the establishment of an abundant, diverse, and functional microbiota, which will properly educate the immune system to develop the oral tolerance later in life. Babies born full term and vaginal delivery, prolonged breastfeeding and the interaction with the family environment have been reported to promote the establishment of a functional intestinal microbiota (Milani et al., 2017), while factors such as premature delivery, cesarean section, insufficient breastfeeding and administration of antibiotics, or their combinations, are associated with ineffective microbiota development and immune disorders or inflammatory-based diseases during infancy and childhood, such as overweight, obesity, allergies, inflammatory bowel disease, or GI and respiratory infections (Tamburini et al., 2016). This combination of modern health practices and life-style has led to a gradual loss in microbial abundance and diversity in the gut, considered a microbe in constriction (Moeller, 2017), leading to a vulnerability of the "industrialized microbiota" (Sonnenburg \& Sonnenburg, 2019).

In this context, diet, age, stress, and diseases can cause increases or decreases in relative abundance and diversity of bacterial species in GI. The persistent imbalance of gut's microbial community, named dysbiosis, relates to some intestinal or extra intestinal diseases (Belizário \& Faintuch, 2018). Being microbial diversity an indicator of potential microbiota endurance and resilience capacity, evidence for the association of the composition of the pharyngeal microbiota with SARSCoV-2 infection was reported (Budding et al., 2020). These authors observed age-dependency of the pharyngeal microbiota composition, being less diverse in older people. This less-diverse profile along age may contribute to explain the enhanced susceptibility of the elderly to COVID-19. However, further studies are needed to support this 


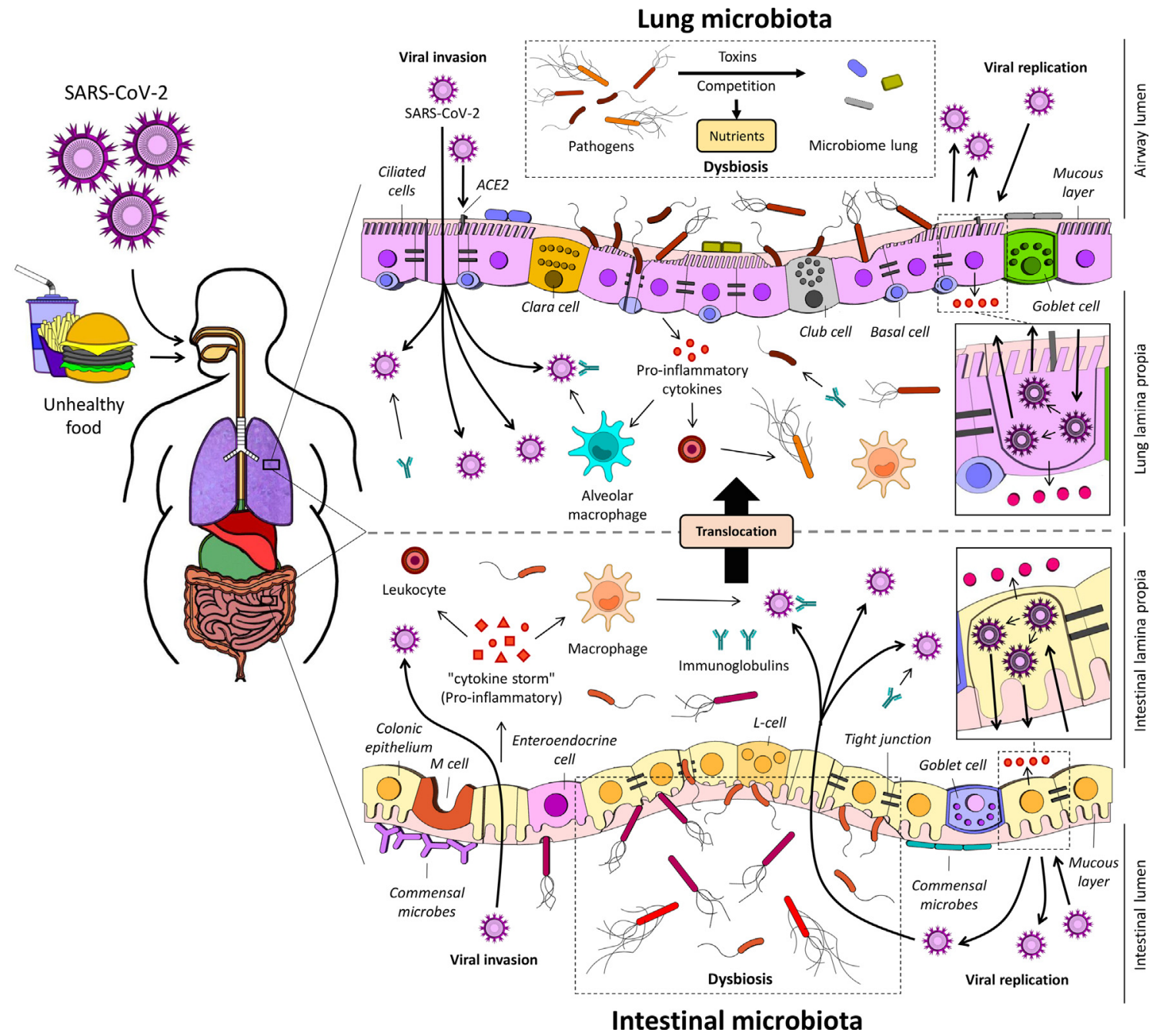

Fig. 1. Dysbiosis process, a perturbation of the microbial community, it may decrease the microbiota diversity, shift the its composition and, consequently, facilitate the invasion and viral replication. It might create an inflammatory environment explored by SARS-CoV-2. Pathogens microbes and virus contribute toward an intestinal and lung barrier dysfunction, with liberations of pro-inflammatory cytokines, promoting a "cytokine storm". Unhealthy diet might reduce the phagocytic activity and modulation of the production of immunoglobulins/antibodies that mediate host defense, lowering the elimination intracellular pathogens and the immune response. ACE2, angiotensin-converting enzyme 2; L-cell, enteroendocrine L-cell; M cell, microfold cell; SARS-CoV-2, severe acute respiratory syndrome.

hypothesis.

Dysbiosis microbiome may create an inflammatory environment that the coronavirus can exploit. Gut-related inflammatory proteins, cytokines, are amplified by more cytokines when coronavirus hits. The combined inflammation may ignite a "cytokine storm"-a runaway immune reaction that can cause more damage than the virus itself, including multiorgan injury (Yang et al., 2020).

A recent Chinese study identified marker bacterial related with COVID-19 susceptibility. Based on the COVID-19 patient data, they constructed a blood proteomic risk score (PRS) for the prediction of COVID-19 progression to clinically severe phase. Then, Ruminococcus gnavus was positively correlated with inflammation, while Clostridia spp. was negatively correlated. They also found a strong association between these bacteria, the PRS, and COVID-19 severity, but only in older age groups. In additional, they looked at a subgroup of 301 noninfected people over a three-year period. Intriguingly, they found that microbiome alterations occurred before the change was reflected by the PRS, making it plausible that dysbiosis causes the protein alterations and not the other way around (Gou et al., 2020).

Then, dietary strategies for the promotion of the gut microbiota, and thus the strengthening of the immune system associated with the gut, include increased consumption of fiber and prebiotics (Holscher, 2017), and incorporating fermented foods (Marco et al., 2017), and probiotics (Zmora et al., 2019) into the diet. The provision of viable microorganisms to the gut achieved by probiotics and certain fermented foods carrying viable microbes means that, during the time they remain in the gut environment, they may perform some of the functions normally carried out by native microbes, in a context of often impoverished microbiota. Probiotics, prebiotics and fermented foods carrying viable microorganisms may be a booster to the activity of the microbiota and the intestinal immunity (Ashraf \& Shah, 2014).

\section{Fermented foods and probiotics}

Fermented foods are those foods produced by microbial action and their enzymes under controlled conditions. Fermentation prolongs the shelf life of the originating food, improves its digestibility, making many of its nutrients more digestible. Fermentation also produces a number of metabolites and microorganisms with potential health effects (Tamang et al., 2020). Fermented foods are a very diverse family of foods, which differ in their nutritional value and microbiological composition, as well as in their potential beneficial effects for health, or those already established through well designed clinical efficacy studies. Some fermented foods do not contain microorganisms (wine, 


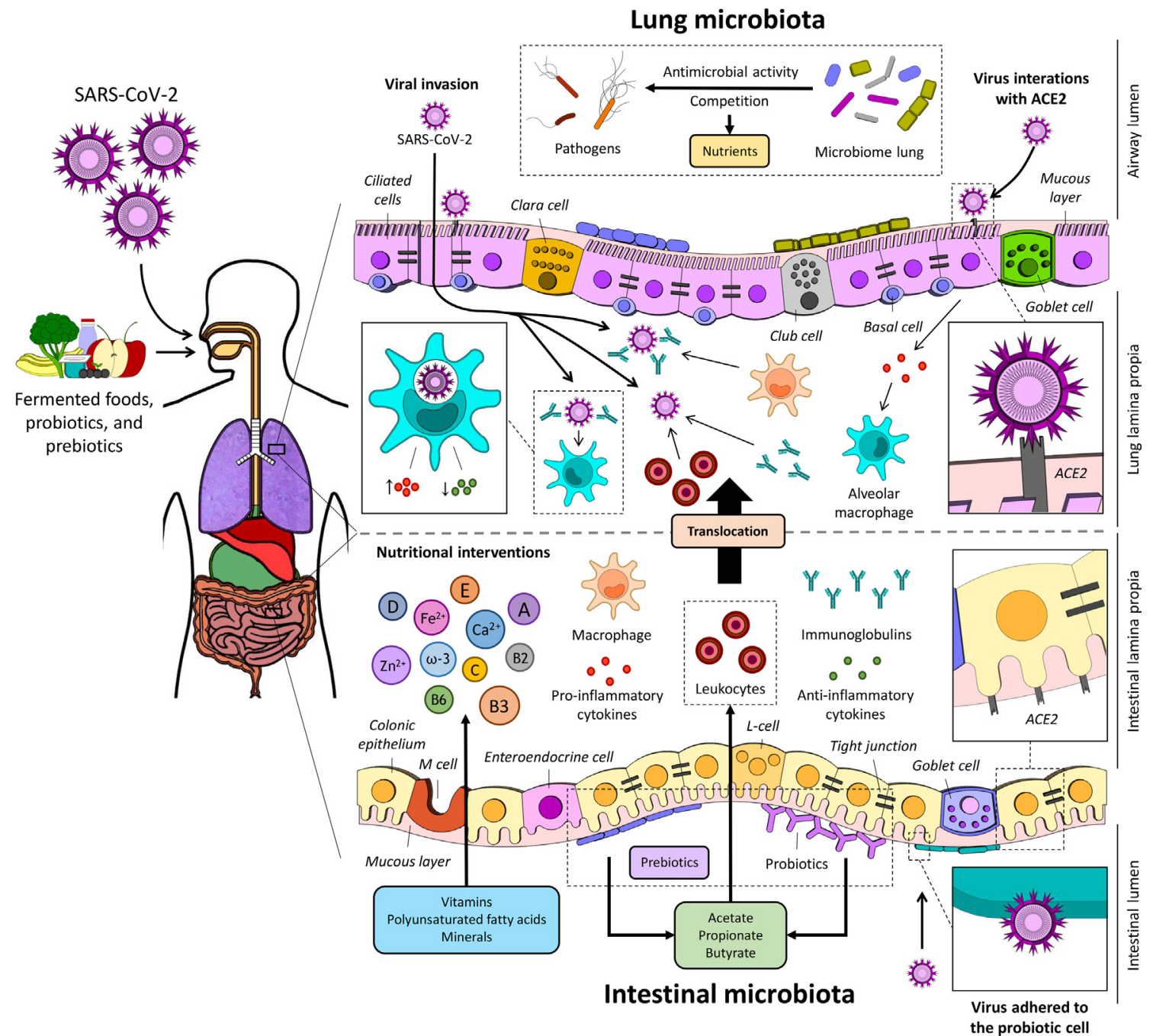

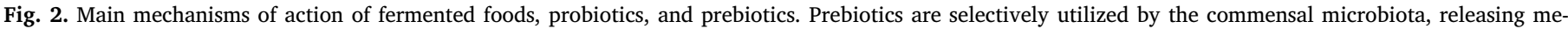

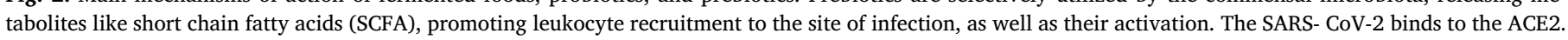

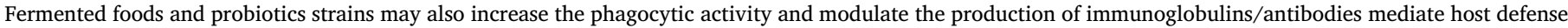

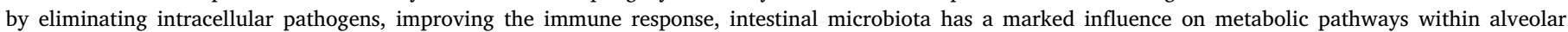

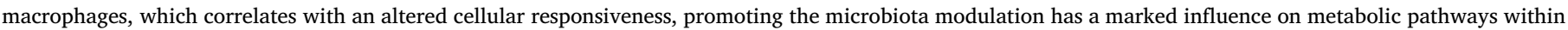

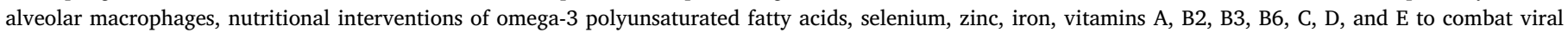
infections. ACE2, angiotensin-converting enzyme 2; L-cell, enteroendocrine L-cell; M cell, microfold cell; SARS-CoV-2, severe acute respiratory syndrome.

beer), or the microorganisms are not viable (sourdough bread, pasteurized sauerkraut), while others may contain living microorganisms, such as yoghurt, yoghurt with probiotics, kefir or kombucha. On the other hand, in some of them, the microbiological composition is known in advance (yoghurt, yoghurt with probiotics), while in others it is not possible to know which microorganisms are present in a given batch (kefir, kombucha, sauerkraut).

Probiotics are live microorganisms that, when administered in adequate amounts, confer a health benefit on the host (Hill et al., 2014), whereas prebiotics are substrates that are selectively utilized by host microorganisms conferring a health benefit, including carbohydrate and non-carbohydrate substances (Gibson et al., 2017). Probiotics can be found in food supplements or in foods, fermented (yoghurt, fermented oats) or not (fruit juices), being yoghurt the most widely used food as a vehicle for probiotics (Syngai et al., 2016). The most widely used probiotics in supplements belong to the genera Lactobacillus, Bifidobacterium, Saccharomyces, and Bacillus, while Lactobacillus and Bifidobacterium are almost exclusively used in foods. The characteristics that a probiotic strain must display are: 1) identity (genera, species, and strain denomination); 2) to be viable in the supplement or food at the moment of intake; and 3) a human efficacy study that demonstrates its beneficial effects. There is scientific evidence about the ability of probiotics to promote gut immunity (Sánchez et al., 2017) and, for the moment, a modest evidence of their role in reducing the severity of acute upper respiratory tract infections (AURTI) (Hao et al., 2015). The use of specific probiotics was recently proposed as a way to contribute to flatten the curve of coronavirus disease (Baud et al., 2020).

Fermented foods are not a synonym of probiotics, and vice versa. Not all fermented food can be regarded as probiotics and not all probiotics are delivered through fermented foods. For example, kefir microbiota is dependent on its origin (Gao \& Li, 2016). In addition, the microbiota of kefir changes along the successive subcultivations of the kefir grains used to produce this fermented food (Gao et al., 2015). Then, technically products with undefined microbiota such as kefir, sauerkraut or kombucha, do not qualify as probiotics (Reid et al., 2019), however these fermented foods can have potential beneficial effects due to their content of viable microorganisms (Rosa et al., 2017). In case of yoghurt (milk fermented by Streptococcus thermophilus and Lactobacillus delbrueckii subsp. bulgaricus) added of selected probiotic 


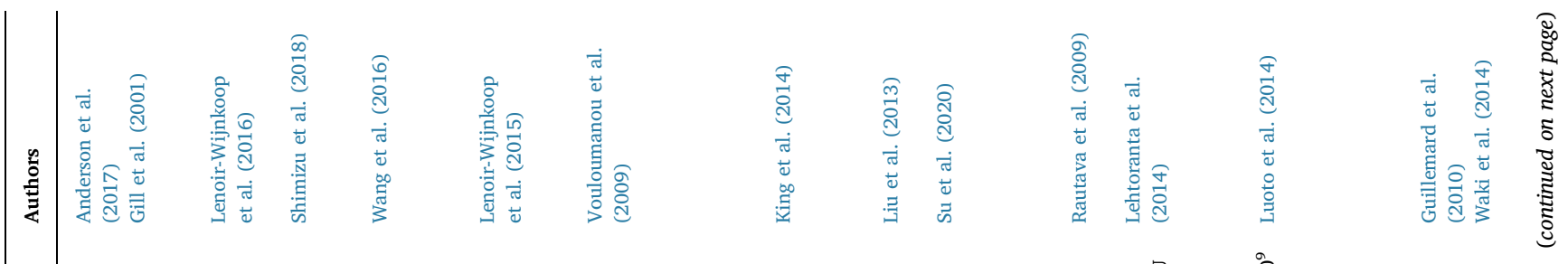

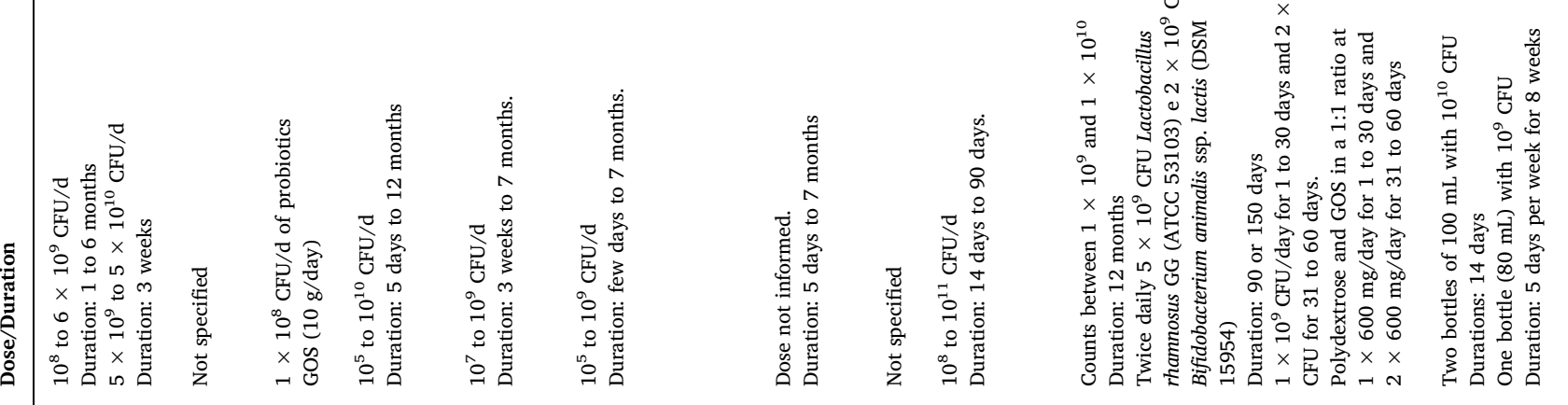

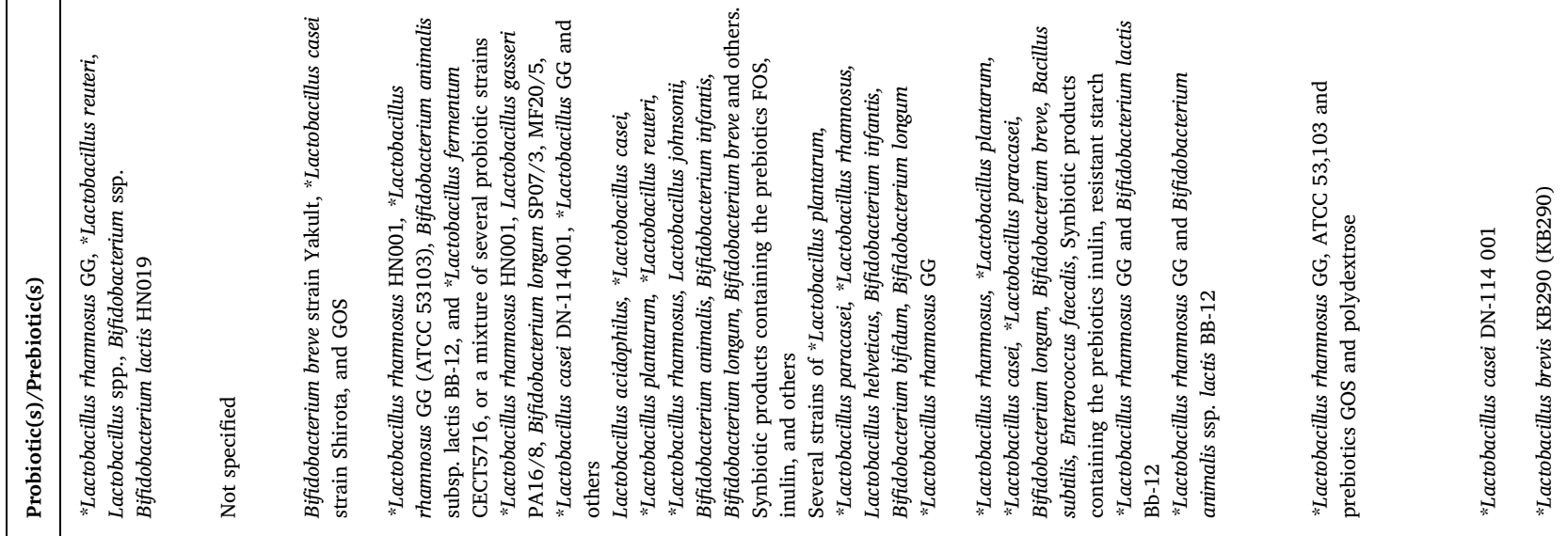

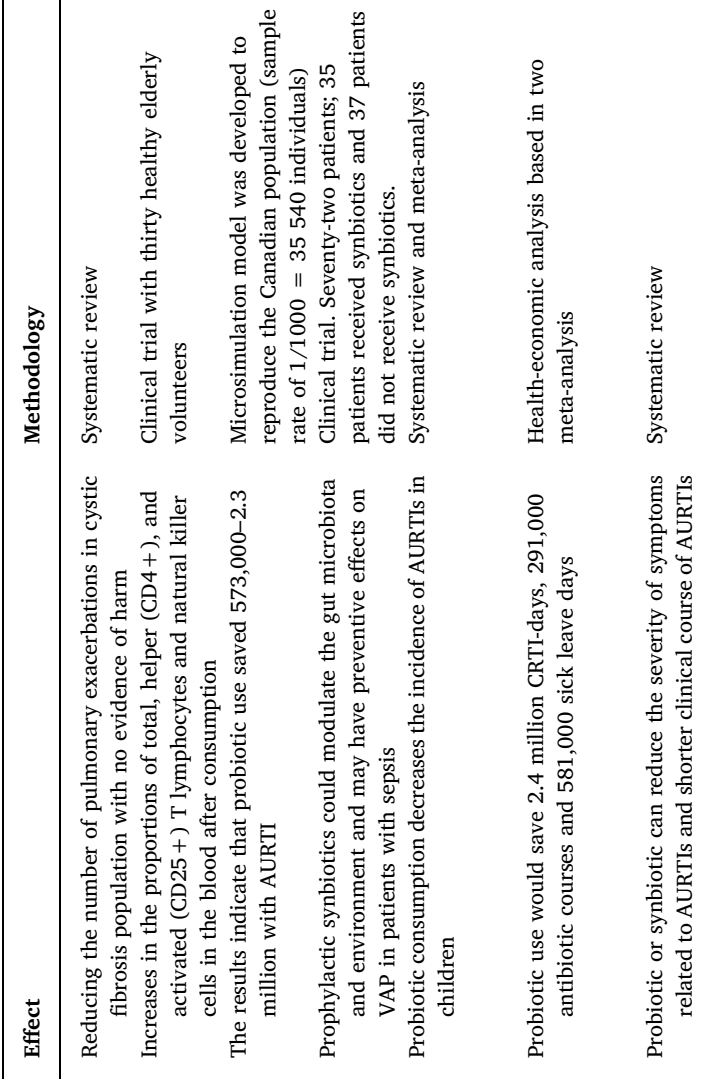
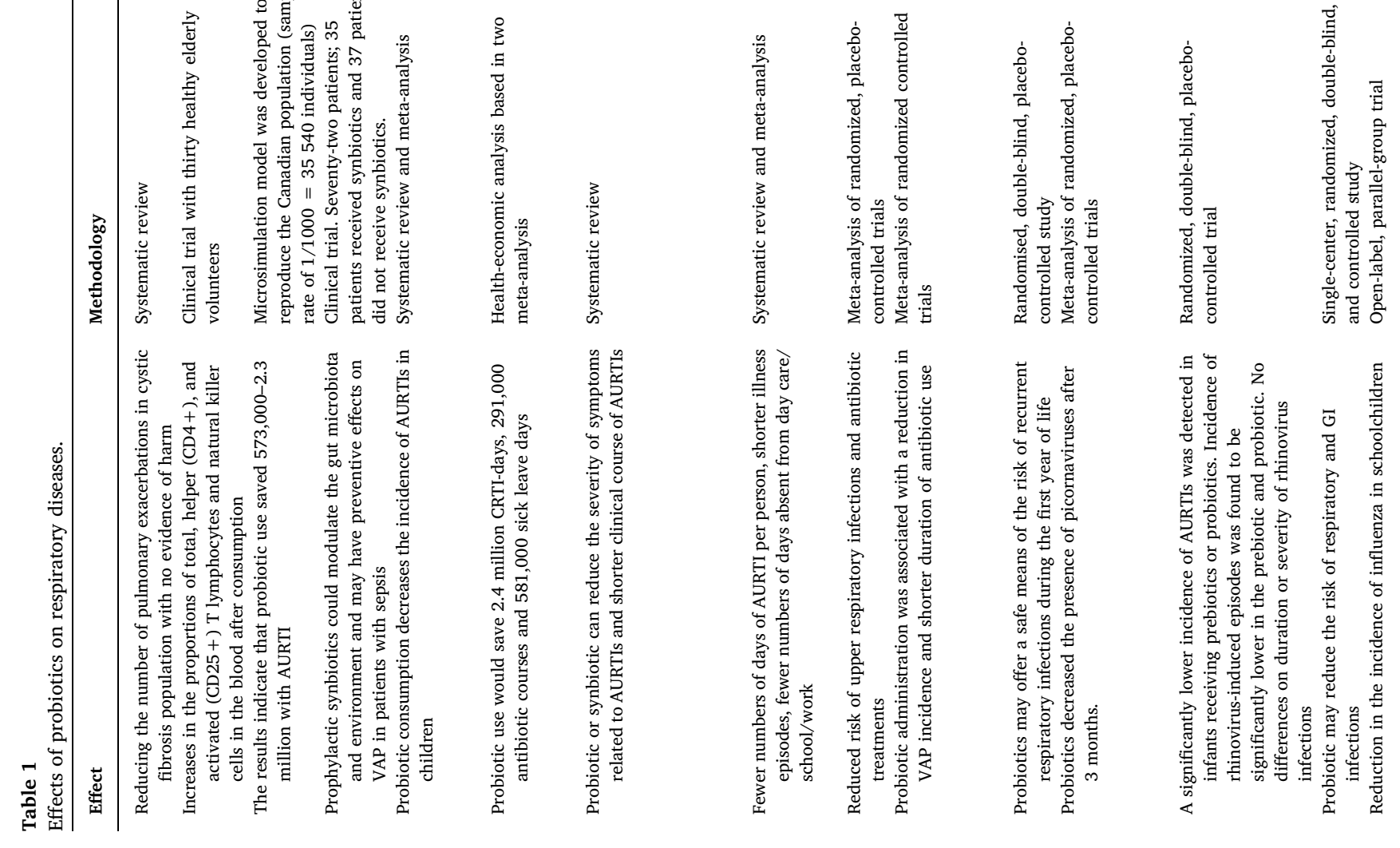
cultures (often belonging to species such Bifidobacterium lactis or Lacticaseibacillus casei, Lacticaseibacillus paracasei, Lacticaseibacillus rhamnosus, formerly known as Lactobacillus casei, Lactobacillus paracasei, and Lactobacillus rhamnosus), the terms fermented foods and probiotics both apply. It is worth noting that the genera Lactobacillus has been recently re-classified and some names changed (Zheng et al., 2020). Another product where both terminologies fit is the product obtained by the mixture of oat fermented with the probiotic strains Lactiplantibacillus plantarum 299v (formerly known as Lactobacillus plantarum 299v) and fruit pulps (Molin, 2001), that can be found in many Nordic countries. An increasing interest in fermented foods was witnessed over the last several years (Taylor et al., 2020). Profiting the spare time while being locked down during the quarantine held in many countries due to the COVID-19 pandemic, many people improved their skills or discovered food fermentation as a way of ingesting live microbes with the potential of promoting gut immunity to better face a possible infection. In a context of impoverished and threatened intestinal microbiota, the consumption of home-made fermented foods (yoghurt, kefir, sauerkraut, kombucha) or the incorporation into the diet of commercial products containing probiotics and prebiotics, as food or food supplements, is part of a comprehensive nutritional strategy to enhance the function of the gut microbiota, to promote mucosal immunity and potentially upper respiratory tract immunity, to be potentially better prepared to face viral or bacterial infections caused by respiratory syndromes.

It is worth mentioning the Zhejiang experience in the management of COVID-19. The National Clinical Research Center for Infectious Diseases, the First Affiliated Hospital of Zhejiang University School of Medicine, is the primary medical care center for COVID-19 in the Province of Zhejiang. An expert consensus protocol was developed by the National Health Commission and National Administration of Traditional Chinese Medicine, focused on "four-anti and two-balance" strategies for clinical practice in case of infected patients. This protocol included antivirus, anti-shock, anti-hypoxemia, anti-secondary infection, and maintaining of water, electrolyte, acid base balance and intestinal microbial balance through nutritional support and application of prebiotics or probiotics to regulate the balance of intestinal microbiota and to reduce the risk of secondary infection due to bacterial translocation (Xu, Cai, et al., 2020).

\section{Probiotics in the prevention of respiratory disease}

Researchers from several countries have been working on the search for effective treatment against COVID-19 and for the development of a vaccine against the SARS-CoV-2 virus. However, there are no drugs approved by the Food and Drug Administration (FDA) so far, and a vaccine will not be available in the near future (Baud et al., 2020; COVID-19 Treatment Guidelines Panel, 2020). For the moment, a clinical trial is being performed on the effect of $L$. rhamnosus GG on the microbiome of household contacts exposed to COVID-19 (U.S. National Library of Medicine, Clinical Trial gov Identifier NCT04399252, 2020). Other ongoing studies using probiotics to prevent or treat COVID-19 are "Evaluation of the probiotic Lactobacillus coryniformis K8 on COVID-19 prevention in healthcare workers" (U.S. National Library of Medicine, Clinical Trial gov Identifier NCT04366180, 2020); “Oxygen-ozone as adjuvant treatment in early control of COVID-19 Progression and modulation of the gut microbial flora (Probiozovid)" (U.S. National Library of Medicine, ClinicalTrials.gov Identifier: ClinicalTrials.gov Identifier: NCT04366089, 2020); and "Bacteriotherapy in the treatment of COVID-19 (BACT-ovid)" (U.S. National Library of Medicine, ClinicalTrials.gov Identifier: NCT04368351, 2020).

Some comorbidities, such as obesity and hypertension may increase the risk of a worse prognosis for COVID-19 and require mechanical breathing. In overweight and obese patients, although there is a high food consumption, frequently is observed a deficiency in some nutrients due to unbalanced diet. Zhang and Liu (2020), pointed the importance of the nutritional status of the host to present an efficient immune 
response against RNA viral infections, such as SARS-CoV-2. Their review emphasized the contribution of vitamins A, B2, B3, B6, C, D, E, omega-3 polyunsaturated fatty acids, selenium, zinc, and iron to combat viral infections. Diet fiber might also be beneficial in this context because diets with high fiber content $(30 \mathrm{~g} / \mathrm{d})$ are associated with lower levels of inflammatory markers (King et al., 2007). Infusino et al. (2020) emphasized also the importance of polyphenols (flavonoids, phenolic acids, stilbenes, lignans) to provide health benefits maintaining a proper redox homeostasis.

The excess body weight per se can cause a mechanical difficulty to the lung ventilation process, aggravated by the decrease in muscle strength of the diaphragm and intercostal muscles. In obese individuals it is observed an increased number of ACE2-expressing cells due to more adipose tissue present (Jia et al., 2020). The overproduction of proinflammatory cytokines observed in COVID-19 can be especially harmful for obese patients, since obesity is a condition of systemic lowgrade inflammation. Pneumonia will be present in mild or more aggressive COVID-19, affecting adults or children (WHO, 2020), as a consequence the lungs will become inflamed and filled with fluid leading to breathing difficulties causing shortness of breath that can culminate to ARDS that can be fatal.

The healthy lung has its specific microbiota obtained by microaspiration and inhalation which can be composed by bacteria, molds and virus. The dynamic of microorganisms that access the lung will be determined by three factors: immigration, elimination, and the relative growth rates of its members (Bassis et al., 2015). The prominent genera in healthy subjects include Prevotella, Veillonella and Streptococcus, however the Veillonella spp. and Prevotella spp. can also be associated with the presence of inflammatory cells in the lung (Bassis et al., 2015; Fanos et al., 2020; Larsen et al., 2014). On the other hand, Pseudomonas spp. is rare in a healthy lung and Proteobacteria can be found in the respiratory tract of intubated preterm newborns (Fanos et al., 2020). In ARDS, the lung microbiota becomes rich in bacteria from the gut, such as Bacteroidetes and Enterobacteriaceae gut probably because of condition of hyper-permeable gut what facilitates bacterial translocation through the colon wall and reach the lung (Fanos et al., 2020). Dysbiosis in gut microbiota has been implicated in several lung diseases, including allergy, asthma and cystic fibrosis (Anand \& Mande, 2018). Fig. 1 shows the lesions in the pulmonary and intestinal epithelium resulting of the prevalence of pathogens microorganisms that contribute to an inflammatory environment, in which it may be explored by SARS-CoV-2 in both microbiota.

There is a possible gut-lung axis which mediates intensive dialogues between the two organs with both microbial and immune interactions (Anand \& Mande, 2018; Enaud et al., 2020). The microbiota may be responsible of a crucial role in response to lung bacterial infections, but the mechanistic basis needs to be deeper investigated (Brown et al., 2017; Enaud et al., 2020). Brown et al. (2017) begun to decipher this mechanism, comparing the effect of the microbiota on the innate response to pulmonary clearance of Streptococcus pneumoniae (Gram-positive) and Klebsiella pneumoniae (Gram-negative) using wild-type C57BL/6 mice. They found that Limosilactobacillus reuteri (formerly known as Lactobacillus reuteri), Enterococcus faecalis, Lactobacillus crispatus, and Clostridium orbiscindens promote resistance to lung infection through Nod2 (nucleotide-binding oligomerization domain containing 2) and GM-CSF (granulocyte-macrophage colony-stimulating factor) signaling, which stimulates pathogen killing and clearance by alveolar macrophages through extracellular signal regulated kinase signaling.

The gut microbiota has a marked influence on metabolic pathways within alveolar macrophages, which correlates with an altered cellular responsiveness. Macrophages in microbiota-depleted mice have a diminished capacity to phagocytose $S$. pneumoniae and demonstrate a reduced cellular responsiveness towards lipoteichoic acid and lipopolysaccharide (Schuijt et al., 2016). Metabolites produced by the gut microbiota modulate not only the gastro-intestinal immunity, but also impact distal organs like lung and brain (Anand \& Mande, 2018).
Acetate, propionate and butyrate are short chain fatty acids (SCFA) produced at high concentration by bacteria in the gut and subsequently released to the bloodstream. Le Poul et al. (2003) identified two specific receptors of SCFA promoting leukocyte recruitment to the site of infection, as well as their activation. Faced with any infection the immune system is able to provide tailored responses to different antigens helping at the defense against respiratory infections. Specialized cells secrete immunoglobulins/specific antibodies and mediate host defense by eliminating intracellular pathogens and by killing virus infected cells (Gil \& Guarner, 2004). Fig. 2 shows mechanisms of protection conferred by beneficial microbes to keep the defenses against viral infection.

Given the very limited therapeutic options available to treat COVID19 alternative methods to control the spread of the disease are essential (Zhang \& Liu, 2020). A possible strategy would be to modulate the microbiome using probiotics, especially Bifidobacteria and Lactobacilli species (Fanos et al., 2020; Mak et al., 2020). Probiotics may facilitate the resolution of respiratory symptoms (Anderson et al., 2017; Fanos et al., 2020), but until this moment there are no scientific evidence that probiotics administered alone or in combination with prebiotics may prevent or treat symptoms of COVID-19.

On the other hand, the literature points to the therapeutic potential of employing probiotics for various disorders of the respiratory system, as presented at Table 1 . There is accumulating evidence supporting the use of probiotics as preventive measure to reduce AURTI frequency, duration and the use of medications (Lenoir-Wijnkoop et al., 2016).

Shimizu et al. (2018) evaluated synbiotic supplementation (Bifidobacterium breve strain Yakult, L. casei strain Shirota, and galactooligosaccharides) on sepsis patients who were mechanically ventilated in the intensive care unit. They observed a reduction in pneumonia associated with mechanical ventilation (VAP) in the group supplemented with symbiotic compared to the placebo. At Cochrane Library a systematic review on probiotics for preventing VAP was presented (Bo et al., 2014) indicating some evidence that probiotics may reduce the incidence of this condition. The probiotics included in this study were L. rhamnosus, L. plantarum, and Bifidobacterium longum (Bo et al., 2014). Another Cochrane review on the effect of probiotics for preventing AURTI evaluated 10 studies and found that compared to placebo, probiotics may reduce the number of participants with AURTI and may reduce the number of participants who used antibiotics (Sæterdal et al., 2012). Lenoir-Wijnkoop et al. (2016) observed a strong potential of probiotic supplementation to reduce the use of antibiotic and reduction of AURTI events. According to the model applied on the study it was projected a higher relative benefit of probiotic consumption among children $<10$ years old, to individuals living in a community setting, and those not vaccinated against influenza.

Mechanical ventilation itself poses a risk of co-infections that can prolong the patient's stay in the hospital and cause new health problems, such as VAP. Su et al. (2020) carried out a meta-analysis of randomized clinical trials that compared the use of probiotics in the prevention of VAP. Among the studies that met the inclusion criteria 6 used single probiotics (L. rhamnosus, L. plantarum 299 or L. casei), 5 used multiple probiotics and 4 a synbiotic formula (detailed in Table 1). According to the meta-analysis, probiotics appear to reduce the incidence of VAP caused by Pseudomonas aeruginosa (Su et al., 2020).

Virus attachment to a host cell represent an essential step in viral infection and probiotics may be able to directly bind the virus and disrupt the infection process (Infusino et al., 2020). Lehtoranta et al. (2014) evaluated if L. rhamnosus GG and Bifidobacterium animalis ssp lactis BB-12 were able to decrease nasopharyngeal occurrence of respiratory virus in conscripts. They observed that the probiotics evaluated decreased the presence of picornaviruses, proposing that they would play a role against viruses causing common cold (Lehtoranta et al., 2014). Luoto et al. (2014) observed reduction of risk of rhinovirus infection of preterm infants supplemented with galacto-oligosaccharide and polydextrose mixture and the probiotic L. rhamnosus GG.

The exact mechanism(s) of the antiviral activity of probiotics is not 
completely clear. However, according to Infusino et al. (2020) it can be summarized as: by reinforcing the mucosal innate immune response, by reducing intestinal permeability; and by affecting the systemic acquired immune response through a regulatory and anti-inflammatory effect.

A limitation pointed to some of the cited clinical studies is the lack of information about the strain(s) of probiotic microorganism(s) in some of them, which would be useful information, since many of the health-promoting effects of probiotics are strain-dependent.

\section{Conclusion and future perspectives}

Facing this pandemic is driving us to find new answers and ways to face the challenges. In this way, a close relationship between COVID-19 and the intestinal microbiota might explain gut dysfunctions complications in some patients with more severe clinical course of the disease (Fanos et al., 2020). However, fermented foods, probiotics, prebiotics, and synbiotics are capable to modulate the gut and probably at distant sites such as the respiratory tract. Specific therapeutic strategies can be proposed, such as the use of probiotic for patients with COVID-related gastro-intestinal symptoms and in those with mild-moderate systemic symptoms, trying to prevent cytokine storm (Infusino et al., 2020). Finally, scientific knowledge must still advance to establish sciencebased recommendations of prebiotics and probiotics to prevent or treat COVID-19.

\section{Ethics statement}

The authors state there are no ethical concerns in the article.

\section{CRediT authorship contribution statement}

Adriane E.C. Antunes: Methodology, Investigation, Writing-original draft. Gabriel Vinderola: Methodology, Investigation, Writingoriginal draft. Douglas Xavier-Santos: Writing - review \& editing. Katia Sivieri: Conceptualization, Methodology, Investigation, Writingoriginal draft.

\section{Declaration of Competing Interest}

The authors declare to have no conflicts of interest.

\section{References}

Anand, S., \& Mande, S. S. (2018). Diet, microbiota and gut-lung connection. Frontiers in Microbiology, 9, 2147. https://doi.org/10.3389/fmicb.2018.02147.

Anderson, J. L., Miles, C., \& Tieney, A. C. (2017). Effect of probiotics on respiratory, gastrointestinal and nutritional outcomes in patients with cystic fibrosis: A systematic review. Journal of Cystic Fibrosis, 16(2), 186-197. https://doi.org/10.1016/j.jcf.2016. 09.004.

Ashraf, R., \& Shah, N. P. (2014). Immune system stimulation by probiotic microorganisms. Critical Reviews in Food Science and Nutrition, 54(7), 938-956. https://doi.org/ 10.1080/10408398.2011.619671.

Bassis, C. M., Erb-Downward, J. R., Dickson, R. P., Freeman, C. M., Schmidt, T. M., Young, V. B., Beck, J. M., Curtis, J. L., \& Huffnagle, G. B. (2015). Analysis of the upper respiratory tract microbiotas as the source of the lung and gastric microbiotas in healthy individuals. mBio, 6(2), e00037-e115. https://doi.org/10.1128/mBio. 00037-15.

Baud, D., Agri, V. D., Gibson, G. R., Reid, G., \& Giannoni, E. (2020). Using probiotics to flatten the curve of coronavirus disease COVID-2019 pandemic. Frontiers in Public Health, 8, 186. https://doi.org/10.3389/fpubh.2020.00186.

Belizário J. E., \& Faintuch J. (2018). Microbiome and gut dysbiosis. In: R. Silvestre, \& E. Torrado (Eds), Metabolic interaction in infection (1st ed., pp. 459-476). New York Springer, Cham. https://doi.org/10.1007/978-3-319-74932-7 13

Bo, L., Li, J., Tao, T., Bai, Y., Ye, X., Hotchkiss, R. S., Kollef, M. H., Crooks, N. H., \& Deng, X. (2014). Probiotics for preventing ventilator-associated pneumonia. Cochrane Database of Systematic Reviews, 25(10), CD009066. https://doi.org/10.1002/ 14651858.CD009066.pub2.

Bosch, B. J., van der Zee, R., de Haan, C. A. M., \& Rottier, P. J. M. (2003). The coronavirus spike protein is a class I virus fusion protein: Structural and functional characterization of the fusion core complex. Journal of Virology, 77(16), 8801-8811. https:// doi.org/10.1128/jvi.77.16.8801-8811.2003.

Brown, R. L., Sequeira, R. P., \& Clarke, T. B. (2017). The microbiota protects against respiratory infection via GM-CSF signaling. Nature Communications, 8(1), 1512. https://doi.org/10.1038/s41467-017-01803-x.

Budding, A., Sieswerda, E., Wintermans, B., \& Bos, M. (2020). An age dependent pharyngeal microbiota signature associated with SARS-CoV-2 infection. Preprint with the Lancet. https://doi.org/10.2139/ssrn.3582780.

Cai, X., Ma, Y., Li, S., Chen, Y., Rong, Z., \& Li, W. (2020). Clinical characteristics of 5 COVID-19 cases with non-respiratory symptoms as the first manifestation in children. Frontiers in Pediatrics, 8, 258. https://doi.org/10.3389/fped.2020.00258.

Chen, N., Zhou, M., Dong, X., Qu, J., Gong, F., Han, Y., Qiu, Y., Wang, J., Liu, Y., Wei, Y., Xia, J., Yu, T., Zhang, X., \& Zhang, L. (2020). Epidemiological and clinical characteristics of 99 cases of 2019 novel coronavirus pneumonia in Wuhan, China: A descriptive study. Lancet, 395, 507-513. https://doi.org/10.1016/S0140-6736(20) 30211-7.

COVID-19 Treatment Guidelines Panel (2020). Coronavirus Diseases 2019 (COVID-19) Treatment Guidelines. National Institutes of Health. Available at: https://www. covid19treatmentguidelines.nih.gov/ (accessed May 15th, 2020).

Cryan, J. F., O'riordan, K. J., Cowan, C. S. M., Sandhu, K. V., Bastiaanssen, T. F. S., Boehme, M., Codagnone, M. G., Cussotto, S., Fulling, C., Golubeva, A. V., Guzzetta, K. E., Jaggar, M., Long-Smith, C. M., Lyte, J. M., Martin, J. A., Molinero-Perez, A., Moloney, G., Morelli, E., Morillas, E., ... Dinan, T. G. (2019). The microbiota-gutbrain axis. Physiological Reviews, 99, 1877-2013. https://doi.org/10.1152/physrev. 00018.2018 .

Enaud, R., Prevel, R., Ciarlo, E., Beaufils, F., Wieërs, G., Guery, B., \& Delhaes, L. (2020) The gut-lung axis in health and respiratory diseases: A place for inter-organ and interkingdom crosstalks. Frontiers in Cellular and Infection Microbiology, 10(9), https://doi. org/10.3389/fcimb.2020.00009.

Fanos, V., Pintus, M. C., Pintus, R., \& Marcialis, M. A. (2020). Lung microbiota in the acute respiratory disease: From coronavirus to metabolomics. Journal of Pediatric and Neonatal Individualized Medicine, 9(1), https://doi.org/10.7363/090139.

Gao, W., Zhang, L., Feng, Z., Liu, H., Shigwedha, N., Han, X., Yi, H., Liu, W., \& Zhang, S. (2015). Microbial diversity and stability during primary cultivation and subcultivation processes of Tibetan kefir. International Journal of Food Science and Technology, 50(6), 1468-1476. https://doi.org/10.1111/ijfs.12801.

Gao, X., \& Li, B. (2016). Chemical and microbiological characteristics of kefir grains and their fermented dairy products: A review. Cogent Food \& Agriculture, 2, 127-152. https://doi.org/10.1080/23311932.2016.1272152.

Gibson, G. R., Hutkins, R., Sanders, M. E., Prescott, S. L., Reimer, R. A., Salminen, S. J., Scott, K., Stanton, C., Swanson, K. S., Cani, P. D., Verbeke, K., \& Reid, G. (2017). Expert consensus document: The International Scientific Association for Probiotics and Prebiotics (ISAPP) consensus statement on the definition and scope of prebiotics. Nature Reviews Gastroenterology \& Hepatology, 14(8), 491-502. https://doi.org/10. 1038/nrgastro.2017.75.

Gil, H. S., \& Guarner, F. (2004). Probiotics and human health: A clinical perspective. Postgraduate Medical Journal, 80(947), 516-526. https://doi.org/10.1136/pgmj. 2003.008664.

Gill, H. S., Rutherfurd, K. L., Cross, M. L., \& Gopal, P. (2001). Enhancement of immunity in the elderly by dietary supplementation with the probiotic Bifidobacterium lactis HN019. American Journal of Clinical Nutrition, 74, 833-839. https://doi.org/10.1093/ ajcn/74.6.833.

Gou, W., Fu, Y., Yue, L., Chen, G., Cai, X., Shuai, M., Xu, F., Yi, X., Chen, H., Zhu, Y. J., Xiao, M., Jiang, Z., Miao, Z., Xiao, C., Shen, B., Wu, X., Zhao, H., Ling, W., Wang, J., ... Zheng, J. (2020). Gut microbiota may underlie the predisposition of healthy individuals to COVID-19. MedRxiv. https://doi.org/10.1101/2020.04.22.20076091.

Guillemard, E., Tanguy, J., Flavigny, A. L., Motte, S., \& Schrezenmeir, J. (2010). Effects of consumption of a fermented dairy product containing the probiotic Lactobacillus casei DN-114 001 on common respiratory and gastrointestinal infections in shift workers in a randomized controlled trial. Journal of the American College of Nutrition, 29(5), 455-468. https://doi.org/10.1080/07315724.2010.10719882.

Hao, Q., Dong, B. R., \& Wu, T. (2015). Probiotics for preventing acute upper respiratory tract infections. Cochrane Database of Systematic Reviews, 3(2), CD006895. https:// doi.org/10.1002/14651858.CD006895.pub3.

Hashimoto, T., Perlot, T., Rehman, A., Trichereau, J., Ishiguro, H., Paolino, M., Sigl, V., Hanada, T., Hanada, R., Lipinski, S., Wild, B., Camargo, S. M. R., Singer, D., Richter, A., Kuba, K., Fukamizu, A., Schreiber, S., Clevers, H., Verrey, F., ... Penninger, J. M. (2012). ACE2 links amino acid malnutrition to microbial ecology and intestinal inflammation. Nature, 487, 477-481. https://doi.org/10.1038/nature11228.

Hill, C., Guarner, F., Reid, G., Gibson, G. R., Merenstein, D. J., Pot, B., Morelli, L., Canani, R. B., Flint, H. J., Salminen, S., Calder, P. C., \& Sanders, M. E. (2014). Expert consensus document. The international scientific association for probiotics and prebiotics consensus statement on the scope and appropriate use of the term probiotic. Nature Reviews Gastroenterology and Hepatology, 11, 506-514. https://doi.org/10.1038/ nrgastro.2014.66.

Holscher, H. D. (2017). Dietary fiber and prebiotics and the gastrointestinal microbiota. Gut Microbes, 8, 172-184. https://doi.org/10.1080/19490976.2017.1290756.

Huang, C., Wang, Y., Li, X., Ren, L., Zhao, J., Hu, Y., Zhang, L., Fan, G., Xu, J., Gu, X., Cheng, Z., Yu, T., Xia, J., Wei, Y., Wu, W., Xie, X., Yin, W., Li, H., Liu, M., ... Cao, B. (2020). Clinical features of patients infected with 2019 novel coronavirus in Wuhan. China. Lancet, 395(10223), 497-506. https://doi.org/10.1016/S0140-6736(20) 30183-5.

Infusino, F., Marazzato, M., Mancone, M., Fedele, F., Mastroianni, C. M., Severino, P., Ceccarelli, G., Santinelli, L., Cavarretta, E., Marullo, A., Miraldi, F., Carnevale, R., Nocella, C., Biondi-Zoccai, G., Pagnini, C., Schiavon, S., Pugliese, F., Frati, G., \& d'Ettorre, G. (2020). Diet supplementation, probiotics, and nutraceuticals in SARS CoV-2 infection: A scoping review. Nutrients, 12(6), https://doi.org/10.3390/ nu12061718.

Jia, X., Yin, C., Lu, S., Chen, Y., Liu, Q., Bai, J., \& Lu, Y. (2020). Two things about COVID- 
19 might need attention. Preprints. https://doi.org/10.20944/preprints202002. 0315.v1.

Jin, X., Lian, J. S., Hu, J. H., Gao, J., Zheng, L., Zhang, Y. M., Hao, S. R., Jia, H. Y., Cai, H., Zhang, X. L., Yu, G. D., Xu, K. J., Wang, X. Y., Gu, J. Q., Zhang, S. Y., Ye, C. Y., Jin, C. L., Lu, Y. F., Yu, X., ... Yang, Y. (2020). Epidemiological, clinical and virological characteristics of 74 cases of coronavirus-infected disease 2019 (COVID-19) with gastrointestinal symptoms. Gut, 69, 1002-1009. https://doi.org/10.1136/gutjn 12020-320926.

John Hopkins University (2020). John Hopkins University \& Medicine: Coronavirus Resource Center. Available at: https://coronavirus.jhu.edu/map.html Accessed Jun 02th, 2020.

King, D. E., Egan, B. M., Woolson, R. F., Mainous, A. G., 3rd, Al-Solaiman, Y., \& Jesri, A. (2007). Effect of a high-fiber diet vs a fiber-supplemented diet on C-reactive protein level. Archives of Internal Medicine, 167(5), 502-506. https://doi.org/10.1001/ archinte.167.5.502.

King, S., Glanville, J., Sanders, M. E., Fitzgerald, A., \& Varley, D. (2014). Effectiveness of probiotics on the duration of illness in healthy children and adults who develop common acute respiratory infectious conditions: A systematic review and metaanalysis. British Journal of Nutrition, 112(1), 41-54. https://doi.org/10.1017/ S0007114514000075.

Larsen, J. M., Musavian, H. S., Butt, T. M., Ingvorsen, C., Thysen, A. H., \& Brix, S. (2014). Chronic obstructive pulmonary disease and asthma-associated Proteobacteria, but not commensal Prevotella spp., promote Toll-like receptor 2-independent lung inflammation and pathology. Immunology, 144, 333-342. https://doi.org/10.1111/ imm. 12376.

Le Poul, E., Loison, C., Struyf, S., Springael, J.-Y., Lannoy, V., Decobecq, M.-E., Brezillon, S., Dupriez, V., Vassart, G., Van Damme, J., Parmentier, M., \& Detheux, M. (2003). Functional characterization of human receptors for short chain fatty acids and their role in polymorphonuclear cell activation. Journal of Biological Chemistry, 278(28), 25481-25489. https://doi.org/10.1074/jbc.M301403200.

Lehtoranta, L., Kalima, K., He, L., Lappalainen, M., Roivainen, M., Närkiö, M., Mäkelä, M., Siitonen, S., Korpela, R., \& Pitkäranta, A. (2014). Specific probiotics and virological findings in symptomatic conscrips attending military service in Finland. Journal of Clinical Virology, 60(3), 276-281. https://doi.org/10.1016/j.jcv.2014.03.021.

Lenoir-Wijnkoop, I., Gerlier, L., Bresson, J. L., Le Pen, C., \& Berdeaux, G. (2015). Public health and budget impact of probiotics on common respiratory tract infections: A modelling study. PLoS ONE, 10(4), https://doi.org/10.1371/journal.pone.0122765.

Lenoir-Wijnkoop, I., Gerlier, L., Roy, D., \& Reid, G. (2016). The clinical and economic impact of probiotics consumption on respiratory tract infections: Projections for Canada. PLOS ONE, 11(11), https://doi.org/10.1371/journal.pone.0166232.

Leung, W. K., To, K. F., Chan, P. K., Chan, H. L., Wu, A. K., Lee, N., Yuen, K. Y., \& Sung, J. J. (2003). Enteric involvement of severe acute respiratory syndrome-associated coronavirus infection. Gastroenterology, 125(4), 1011-1017. https://doi.org/10.1016/ s0016-5085(03)01215-0.

Li, Q., Guan, X., Wu, P., Wang, X., Zhou, L., Tong, Y., Ren, R., Leung, K. S. M., Lau, E. H. Y., Wong, J. Y., Xing, X., Xiang, N., Wu, Y., Li, C., Chen, Q., Li, D., Liu, T., Zhao, J., Liu, M., ... Feng, Z. (2020). Early transmission dynamics in Wuhan, China, of novel coronavirus-infected pneumonia. New England Journal of Medicine, 382, 1199-1207. https://doi.org/10.1056/NEJMoa2001316.

Liu, S., Hu, P. W., Du, X., Zhou, T., \& Pei, X. (2013). Lactobacillus rhamnosus GG supplementation for preventing respiratory infections in children: A meta-analysis of randomized, placebo-controlled trials. Indial Pediatrics, 50(4), 377-381. https://doi. org/10.1007/s13312-013-0123-z.

Luoto, R., Ruuskanen, O., Waris, M., Kalliomäki, M., Salminen, S., \& Isolauri, E. (2014). Prebiotic and probiotic supplementation prevents rhinovirus infections in preterm infants: A randomized, placebo-controlled trial. Journal of Allergy and Clinical Immunology, 133(2), 405-413. https://doi.org/10.1016/j.jaci.2013.08.020.

Mak, J., Chan, F., \& Ng, S. C. (2020). Probiotics and COVID-19: One size does not fit all. The Lancet Gastroenterology \& Hepatology, 5(7), 644-645. https://doi.org/10.1016/ S2468-1253(20)30122-9.

Marco, M. L., Heeney, D., Binda, S., Cifelli, C. J., Cotter, P. D., Foligné, B., Gänzle, M., Kort, R., Pasin, G., Pihlanto, A., Smid, E. J., \& Hutkins, R. (2017). Health benefits of fermented foods: Microbiota and beyond. Current Opinion in Biotechnology, 44, 94-102. https://doi.org/10.1016/j.copbio.2016.11.010.

Milani, C., Duranti, S., Bottacini, F., Casey, E., Turroni, F., Mahony, J., Belzer, C., Delgado Palacio, S., Arboleya Montes, S., Mancabelli, L., Lugli, G. A., Rodriguez, J. M., Bode, L., De Vos, W., Gueimonde, M., Margolles, A., Van Sinderen, D., \& Ventura, M. (2017). The first microbial colonizers of the human gut: Composition, activities, and health implications of the infant gut microbiota. Microbiology and Molecular Biology Reviews, 81(4), e00036-e117. https://doi.org/10.1128/MMBR.00036-17.

Moeller, A. H. (2017). The shrinking human gut microbiome. Current Opinion in Microbiology, 38, 30-35. https://doi.org/10.1016/j.mib.2017.04.002.

Molin, G. (2001). Probiotics in foods not containing milk or milk constituents, with special reference to Lactobacillus plantarum 299v. American Journal of Clinical Nutrition, 73(2), 380S-385S. https://doi.org/10.1093/ajcn/73.2.380s.

Namba, K., Hatano, M., Yaeshima, T., Takase, M., \& Suzuki, K. (2010). Effects of Bifidobacterium longum BB536 administration on influenza infection, influenza vaccine antibody titer, and cell-mediated immunity in the elderly. Bioscience, Biotechnology, and Biochemistry, 74(5), 939-945. https://doi.org/10.1271/bbb. 90749.

Panigrahi, P., Parida, S., Nanda, N. C., Satpathy, R., Pradhan, L., Chandel, D. S., Baccaglini, L., Mohapatra, A., Mohapatra, S. S., Misra, P. R., Chaudhry, R., Chen, H. H., Johnson, J. A., Morris, J. G., Paneth, N., \& Gewolb, I. H. (2017). A randomized synbiotic trial to prevent sepsis among infants in rural India. Nature, 548(7668), 407-412. https://doi.org/10.1038/nature23480.

Rautava, S., Salminen, S., \& Isolauri, E. (2009). Specific probiotics in reducing the risk of acute infections in infancy - A randomised, double-blind, placebo-controlled study. British Journal of Nutrition, 101(11), 1722-1726. https://doi.org/10.1017/ S0007114508116282.

Reid, G., Gadir, A. A., \& Dhir, R. (2019). Probiotics: Reiterating what they are and what they are not. Frontiers in Microbiology, 10, 424. https://doi.org/10.3389/fmicb.2019. 00424.

Rivellese, F., \& Prediletto, E. (2020). ACE2 at the centre of COVID-19 from paucisymptomatic infections to severe pneumonia. Autoimmunity Reviews, 19(6), https:// doi.org/10.1016/j.autrev.2020.102536.

Rooks, M. G., \& Garrett, W. S. (2016). Gut microbiota, metabolites and host immunity. Nature Reviews Immunology, 16(6), 341-352. https://doi.org/10.1038/nri.2016.42.

Rosa, D. D., Dias, M., Grześkowiak, Ł. M., Reis, S. A., Conceição, L. L., \& Peluzio, M. (2017). Milk kefir: Nutritional, microbiological and health benefits. Nutrition Research Reviews, 30(1), 82-96. https://doi.org/10.1017/S0954422416000275.

Sæterdal, I., Underland, V., \& Nilsen, E. S. (2012). The effect of probiotics for preventing acute upper respiratory tract infections. Global Advances in Health and Medicine, 1(2), 124-125. https://doi.org/10.7453/gahmj.2012.1.2.014.

Sánchez, B., Delgado, S., Blanco-Míguez, A., Lourenço, A., Gueimonde, M., \& Margolles, A. (2017). Probiotics, gut microbiota, and their influence on host health and disease. Molecular Nutrition \& Food Research, 61(1), https://doi.org/10.1002/mnfr. 201600240.

Schuijt, T. J., Lankelma, J. M., Scicluna, B. P., De souse e Melo, F., Roelofs, J. J., de Boer, J. D., Hoogendijk, A. J., de Beer, R., de Vos, A., Belzer, C., de Vos, W. M., van der Poll, T., \& Wiersinga, W. J. (2016). The gut microbiota plays a protective role in the host defence against pneumococcal pneumonia. Gut, 65(4), 575-583. https://doi.org/10. 1136/gutjnl-2015-309728.

Shimizu, K., Yamada, T., Ogura, H., Mohri, T., Kiguchi, T., Fujimi, S., Asahara, T., Yamada, T., Ojima, M., Ikeda, M., \& Shimazu, T. (2018). Synbiotics modulate gut microbiota and reduce enteritis and ventilator-associated pneumonia in patients with sepsis: A randomized controlled trial. Critical Care, 22(1), 239. https://doi.org/10. 1186/s13054-018-2167-x.

Sonnenburg, J. L., \& Sonnenburg, E. D. (2019). Vulnerability of the industrialized microbiota. Science, 366(6464), eaaw9255. https://doi.org/10.1126/science.aaw9255.

Su, M., Jia, Y., Li, Y., Zhou, D., \& Jia, J. (2020). Probiotics for the prevention of ventilatorassociated pneumonia: A meta-analysis of randomized controlled trials. Respiratory Care, 65(5), 673-685. https://doi.org/10.4187/respcare.07097.

Syngai, G. G., Gopi, R., Bharali, R., Dey, S., Lakshmanan, G. M., \& Ahmed, G. (2016). Probiotics - the versatile functional food ingredients. Journal of Food Science and Technology, 53(2), 921-933. https://doi.org/10.1007/s13197-015-2011-0.

Tamang, J. P., Cotter, P. D., Endo, A., Han, N. S., Kort, R., Liu, S. Q., Mayo, B., Westerik, N., \& Hutkins, R. (2020). Fermented foods in a global age: East meets west. Comprehensive Reviews in Food Science and Food Safety, 19(1), 184-217. https://doi. org/10.1111/1541-4337.12520.

Tamburini, S., Shen, N., Wu, H. C., \& Clemente, J. C. (2016). The microbiome in early life: Implications for health outcomes. Nature Medicine, 22, 713-722. https://doi.org/10. 1038/nm.4142.

Taylor, B. C., Lejzerowicz, F., Poirel, M., Shaffer, J. P., Jiang, L., Aksenov, A., Litwin, N., Humphrey, G., Martino, C., Miller-Montgomery, S., Dorrestein, P. C., Veiga, P., Song, S. J., McDonald, D., Derrien, M., \& Knight, R. (2020). Consumption of fermented foods is associated with systematic differences in the gut microbiome and metabo lome. mSystems, 5(2), e00901-19. https://doi.org/10.1128/mSystems.00901-19.

Thursby, E., \& Juge, N. (2017). Introduction to the human gut microbiota. Biochemical Journal, 474(11), 1823-1836. https://doi.org/10.1042/BCJ20160510.

U.S. National Library of Medicine. (2020). Bacteriotherapy in the treatment of COVID-19 (BACT-ovid) (ClinicalTrials.gov Identifier: NCT04368351, 2020). Available at: https://clinicaltrials.gov/ct2/show/NCT04368351 Accessed Jun 18th, 2020.

U.S. National Library of Medicine. (2020). Effect of Lactobacillus on the microbiome of household contacts exposed to COVID-19 (ClinicalTrials.gov Identifier: NCT04399252). Available at: https://www.clinicaltrials.gov/ct2/show/ NCT04399252 Accessed Jun 08th, 2020.

U.S. National Library of Medicine. (2020). Evaluation of the probiotic Lactobacillus coryniformis K8 on COVID-19 prevention in healthcare workers (Clinical Trial gov Identifier NCT04366180, 2020). Available at: https://clinicaltrials.gov/ct2/show/ NCT04366180 Accessed Jun 18th, 2020.

U.S. National Library of Medicine. (2020). Oxygen-ozone as adjuvant treatment in early control of COVID-19 progression and modulation of the gut microbial flora (PROBIOZOVID) (Clinical Trial gov Identifier NCT04366089, 2020). Available at: https://clinicaltrials.gov/ct2/show/NCT04366089 Accessed Jun 18th, 2020.

Vouloumanou, E. K., Makris, G. C., Karageorgopoulos, D. E., \& Falagas, M. E. (2009). Probiotics for the prevention of respiratory tract infections: A systematic review. International Journal of Antimicrobial Agents, 34(3), e1-e10. https://doi.org/10.1016/ j.ijantimicag.2008.11.005.

Vrese, M., Winkler, P., Rautenberg, P., Harder, T., Noah, C., Laue, C., Ott, S., Hampe, J., Schreiber, S., Heller, K., \& Schrezenmeir, J. (2005). Effect of Lactobacillus gasseri PA $16 / 8$, Bifidobacterium longum SP 07/3, B. bifidum MF 20/5 on common cold episodes: A double blind, randomized, controlled trial. Clinical Nutrition, 24(4), 481-491. https://doi.org/10.1016/j.clnu.2005.02.006.

Waki, N., Matsumoto, M., Fukui, Y., \& Suganuma, H. (2014). Effects of probiotic Lactobacillus brevis KB290 on incidence of influenza infection among schoolchildren: An open-label pilot study. Letters in Applied Microbiology, 59(6), 565-571. https://doi. org/10.1111/lam.12340.

Wang, L., Wang, Y., Ye, D., \& Liu, Q. (2020). Review of the 2019 novel coronavirus (SARS-CoV-2) based on current evidence. International Journal of Antimicrobial Agents, 55(6), https://doi.org/10.1016/j.ijantimicag.2020.105948.

Wang, Y., Li, X., Ge, T., Xiao, Y., Liao, Y., Cui, Y., Zhang, Y., Ho, W., Yu, G., \& Zhang, T. (2016). Probiotics for prevention and treatment of respiratory tract infections in 
children: A systematic review and meta-analysis of randomized controlled trials. Medicine, 95(31), https://doi.org/10.1097/MD.0000000000004509.

World Health Organization. (2020). Clinical management of severe acute respiratory infection (SARI) when COVID-19 disease is suspected: Interim guidance, 13 March 2020. Available at: https://apps.who.int/iris/handle/10665/331446 Accessed Jun 06th, 2020.

Wu, F., Zhao, S., Yu, B., Chen, Y. M., Wang, W., Song, Z. G., Hu, Y., Tao, Z. W., Tian, J. H., Pei, Y. Y., Yuan, M. L., Zhang, Y. L., Dai, F. H., Liu, Y., Wang, Q. M., Zheng, J. J., Xu, L., Holmes, E. C., \& Zhang, Y. Z. (2020). A new coronavirus associated with human respiratory disease in China. Nature, 579(7798), 265-269. https://doi.org/10.1038/ s41586-020-2008-3.

Xu, H., Zhong, L., Deng, J., Peng, J., Dan, H., Zeng, X., Li, T., \& Chen, Q. (2020). High expression of ACE2 receptor of 2019-nCoV on the epithelial cells of oral mucosa. International Journal of Oral Science, 12(8), https://doi.org/10.1038/s41368-0200074-x.

Xu, K., Cai, H., Shen, Y., Ni, Q., Chen, Y., Hu, S., Li, J., Wang, H., Yu, L., Huang, H., Qiu, Y., Wei, G., Fang, Q., Zhou, J., Sheng, J., Liang, T., \& Li, L. (2020). Management of COVID-19: The Zhejiang experience. Zhejiang da xue xue bao. Yi xue ban = Journal of Zhejiang University. Medical Sciences, 49(2), 147-157.

Yang, Y., Shen, C., Li, J., Yuan, J., Yang, M., Wang, F., Li, G., Li, Y., Xing, L., Peng, L., Wei, J., Cao, M., Zheng, H., Wu, W., Zou, R., Li, D., Xu, Z., Wang, H., Zhang, M., ... Liu, Y. (2020). Exuberant elevation of IP-10, MCP-3 and IL-1ra during 902 SARS-CoV-2 infection is associated with disease severity and fatal outcome. MedRxiv. https://doi. org/10.1101/2020.03.02.20029975.

Yin, Y., \& Wunderink, R. G. (2018). MERS, SARS and other coronaviruses as causes of pneumonia. Respirology, 23(2), 130-137. https://doi.org/10.1111/resp.13196.

Zhang, H., Kang, Z., Gong, H., Xu, Da., Wang, J., Li, Z., Cui, X., Xiao, J., Meng, T., Zhou, W., Liu, J., \& Xu, H. (2020). The digestive system is a potential route of 2019-nCov infection: A bioinformatics analysis based on single-cell transcriptomes. bioRxiv. https://doi.org/10.1101/2020.01.30.927806.

Zhang, L., \& Liu, Y. (2020). Potential interventions for novel coronavirus in China: A systematic review. Journal of Medical Virology, 92(5), 479-490. https://doi.org/10 1002/jmv.25707.

Zheng, J., Wittouck, S., Salvetti, E., Franz, C. M. A. P., Harris, H. M. B., Mattarelli, P. O'Toole, P. W., Pot, B., Vandamme, P., Walter, J., Watanabe, K., Wuyts, S., Felis, G. E., Gänzle, M. G., \& Lebeer, S. (2020). A taxonomic note on the genus Lactobacillus: Description of 23 novel genera, emended description of the genus Lactobacillus Beijerinck 1901, and union of Lactobacillaceae and Leuconostocaceae. International Journal of Systematic and Evolutionary Microbiology, 70, 2782-2858. https://doi.org/ 10.1099/ijsem.0.004107.

Zmora, N., Suez, J., \& Elinav, E. (2019). You are what you eat: Diet, health and the gut microbiota. Nature Reviews Gastroenterology \& Hepatology, 16(1), 35-56. https://doi. org/10.1038/s41575-018-0061-2. 